\title{
Feasibility of containing shigellosis in Hubei Province, China: a modelling study
}

\author{
Jia Rui ${ }^{1 \dagger}$, Qi Chen ${ }^{2 \dagger}$, Qiuping Chen ${ }^{3 \dagger}$, Qingqing Hu ${ }^{4}$, Mikah Ngwanguong Hannah5, Zeyu Zhao ${ }^{1}$, Yao Wang ${ }^{1}$, \\ Xingchun Liu', Zhao Lei', Shanshan Yu', Yi-Chen Chiang ${ }^{1}$, Benhua Zhao', Yanhua Su', Bin Zhao ${ }^{6}$ and \\ Tianmu Chen ${ }^{1 *}$ (D)
}

\begin{abstract}
Background: The transmission features and the feasibility of containing shigellosis remain unclear among a population-based study in China.

Methods: A population-based Susceptible - Exposed - Infectious / Asymptomatic - Recovered (SEIAR) model was built including decreasing the infectious period (DIP) or isolation of shigellosis cases. We analyzed the distribution of the reported shigellosis cases in Hubei Province, China from January 2005 to December 2017, and divided the time series into several stages according to the heterogeneity of reported incidence during the period. In each stage, an epidemic season was selected for the modelling and assessing the effectiveness of DIP and case isolation.

Results: A total of 130,770 shigellosis cases were reported in Hubei Province. The median of $R_{\text {eff }}$ was 1.13 (range: 0.86-1.21), 1.10 (range: 0.91-1.13), 1.09 (range: 0.92-1.92), and 1.03 (range: 0.94-1.22) in 2005-2006 season, 20102011 season, 2013-2014 season, and 2016-2017 season, respectively. The reported incidence decreased significantly (trend $X^{2}=8260.41, P<0.001$ ) among four stages. The incidence of shigellosis decreased sharply when DIP implemented in three scenarios $(y=0.1,0.1429,0.3333)$ and when proportion of case isolation increased.
\end{abstract}

Conclusions: Year heterogeneity of reported shigellosis incidence exists in Hubei Province. It is feasible to contain the transmission by implementing DIP and case isolation.

Keywords: Shigellosis, Transmission control, Feasibility, Mathematical model

\section{Background}

Globally, Shigella spp, which causes severe diarrhea and dysentery, is the second leading cause of diarrhea death following rotavirus, and it is estimated that the pathogen causes approximately 210,000 deaths among all ages, including about 63,700 children under the age of five [1]. Despite mortality from diarrhea has declined, its incidence remains high, particularly in economically underdeveloped countries [2,3]. The high-risk groups include

\footnotetext{
* Correspondence: 13698665@qq.com

${ }^{\dagger}$ Jia Rui, Qi Chen and Qiuping Chen contributed equally to this work. 'State Key Laboratory of Molecular Vaccinology and Molecular Diagnostics, School of Public Health, Xiamen University, 4221-117 South Xiang'an Road, Xiang'an District, Xiamen City, Fujian Province, People's Republic of China Full list of author information is available at the end of the article
}

children aged 1 to 4 years old, and some other groups include travelers to areas where dysentery is prevalent and men who have sex with men [2, 4-7]. Because humans are the only host of Shigella spp, diarrhea is transmitted by contact between people and some related life behaviors, while food and water are less common to transmit diarrhea. In addition, flies can spread the pathogen in environments where feces pollute the environment $[8,9]$. Because asymptomatic individuals are unpredictable, the disease burden on the disease is particularly severe worldwide.

At present, the main prevention and control measures of shigellosis include managing the sources of infection, cutting off the transmission route and protecting the 
susceptible population [10-12]. Early detection of patients and carriers, timely isolation and thorough treatment are important measures to control shigellosis. The ways of cutting off transmission way includes managing water, excrement and food, managing the transmission through flies and washing hands before eating and after using the toilet [13].

The quantitative prediction and early warning of epidemic situation based on the model has become the focus of the public health field, and more quantitative prediction data have been gradually added to the qualitative assessment of trend judgment. The ARIMA model, GM $(1,1)$ gray model, prospective space-time scan statistic, Markov model and mathematical model such as a waterborne pathogen model termed the SusceptibleInfectious-Recovered-Water (SIRW) model, are commonly used to forecast the incidence of bacillary dysentery [9, 14-16]. Considering the asymptomatic infection, we previously built a Susceptible-Exposed-Infectious/Asymptomatic-Recovered-Water (SEIARW) model to simulate the transmission and to assess the effectiveness of the key interventions in a small-scale outbreak in a school [14]. However, the transmission features and the feasibility of containing the transmission remain unclear among a whole population in a large outbreak in China. According to our previous researches [14, 17], Susceptible - Exposed - Infectious / Asymptomatic - Recovered - Water (SEIARW) model, in which two routes (person-to-person and reservoir-to-person) were considered, could be used to simulate the enteric infectious diseases including shigellosis. However, the latest research showed that shigellosis transmits primarily from person-to-person [2]. Considering the high coverage of the municipal water systems which provide the disinfected water in China and reservoir-to-person transmission only occasionally reported in small scale outbreak in schools in rural areas [18, 19], we developed a whole-population-based Susceptible - Exposed - Infectious / Asymptomatic - Recovered (SEIAR) model (denoted as Model 1) which only includes the transmission route of person-to-person [20-22].

This study collected data on the incidence of bacterial dysentery in Hubei Province. The aim was to find the better prevention and control measures by simulating the effectiveness of symptomatic infection and simulating the effectiveness of different isolation rates, so as to reduce the disease burden.

\section{Methods}

\section{Study design}

We conducted a time series study in shigellosis cases reported in Hubei Province from January 2005 to November 2017. We performed a modelling study to simulate the incidence of the transmission and to assess the effectiveness of intervention to contain the transmission in the area.

This effort of disease control was part of CDC's routine responsibility in Hubei Province; therefore, institutional review and informed consent were not required for this study. All data analyzed were anonymized.

\section{Data collection}

Hubei Province, locating at the north of the Dongting Lake and in the central of China, has a population of more than 58 million. This study was based on a dataset of reported Shigellosis cases was built from January 2005 to December 2017 in the province. The illness onset date of each case was included in the data. Cases were reported from doctors in clinics or hospitals in Hubei province and were identified following the case definitions with three categories: 1) Suspected cases; 2) Clinically diagnosed cases; 3) Confirmed cases, which were based on the "Diagnostic criteria for bacterial and amoebic dysentery (WS287-2008)" announced by the National Health Commission of the People's Republic of China. The detailed definitions of the three categories above can be consulted from existing literature [23]. In this study, we included clinically diagnosed cases and confirmed cases for the analysis.

\section{The transmission models}

In the model, people were divided into susceptible $(S)$, exposed $(E)$, infectious $(I)$, asymptomatic $(A)$, and recovered $(R)$ individuals. The equations of the model are as follows:

$$
\begin{aligned}
& \frac{d s}{d t}=-b s(i+k a) \\
& \frac{d e}{d t}=b s(i+k a)-\omega e \\
& \frac{d i}{d t}=(1-p) \omega e-\gamma i \\
& \frac{d a}{d t}=p \omega e-\gamma^{\prime} a \\
& \frac{d r}{d t}=\gamma i+\gamma^{\prime} a
\end{aligned}
$$

In the model, $N$ is assumed to denote the total population size and $s=S / N, e=E / N, i=I / N, a=A / N, r=R / N$, and $b=\beta N$. The parameters $\beta, k, \omega, p, \gamma$, and $\gamma^{\prime}$ are transmission relative rate, relative transmissibility of asymptomatic to symptomatic individuals, incubation relative rate, proportion of asymptomatic individuals, infectious period relative rate of symptomatic individuals, and infectious period relative rate of asymptomatic individuals, respectively. 
Because of the interventions or the decreasing proportion of susceptible individuals due to the spread of the pathogen and other reasons providing the difficulty to estimate basic reproduction number $\left(R_{0}\right)$, which is defined as the expected number of secondary infections that result from introducing a single infected individual into an otherwise susceptible population [17, 24-26], effective reproduction number $\left(R_{\text {eff }}\right)$ is commonly employed instead [27]. From the definition, it is clear that when $R_{\text {eff }}>1$, the disease is able to spread in the population. If $R_{\text {eff }}<1$, the infection will be cleared from the population.

In the Model $1, R_{\text {eff }}$ was calculated by the equation as follows:

$$
R_{e f f}=b s\left(\frac{1-p}{\gamma}+\frac{k p}{\gamma^{\prime}}\right)
$$

\section{Decreasing the infectious period}

Asymptomatic individuals were not able to be monitored commonly because of lacking relative symptoms including diarrhea, fever, etc. In this study, we simulated the effectiveness of decreasing the infectious period (DIP) of symptomatic individuals. DIP depends on the following conditions: 1) infected individuals would go to hospitals or clinics as soon as possible when they get the symptoms of the infection; 2) the ability of the hospitals or clinics to diagnose and treat the infection (giving the sensitive antibiotics to control the infection). Obviously, the earlier the infected individuals diagnosed and treated, the shorter the infectious period (IP) would be. We simulated the mixed effectiveness of DIP in three scenarios: 1$) \quad \mathrm{IP}=10$ days $(\gamma=0.1) ; 2) \quad \mathrm{IP}=7$ days $(\gamma=$ $0.1429)$; and 3) IP $=3$ days $(\gamma=0.3333)$ using Model 1.

\section{Case isolation}

In this study, we simulated the effectiveness of case isolation. When cases were diagnosed, the intervention was implemented by the following: 1) the severe cases were isolated in hospital; and 2) the mild cases were quarantined immediately at home and a primary public health provider would perform follow-up visits and provide guidance on quarantine, concurrent disinfection, and terminal disinfection. Because asymptomatic individuals could not been monitored, we assumed that case isolation was only focused on symptomatic individuals. Therefore, we built a Susceptible - Exposed - Infectious/Asymptomatic - Recovered - Quarantined (SEIA $\mathrm{RQ})$ model in which quarantined individuals was denoted as $Q$. We set $q=Q / N$, and $r_{1}, r_{2}$, and $r_{3}$ refer to recovered individuals moved from $A, I$, and $Q$ populations, respectively. The flowchart of SEIARQ model (Model 2) was shown in Fig. 1 and the equations of the model are as follows:

$$
\begin{aligned}
& \frac{d s}{d t}=-b s(i+k a) \\
& \frac{d e}{d t}=b s(i+k a)-\omega e \\
& \frac{d i}{d t}=(1-p) \omega e-(1-m) \gamma i-m i \\
& \frac{d a}{d t}=p \omega e-\gamma^{\prime} a \\
& \frac{d q}{d t}=m i-\gamma q \\
& \frac{d r_{1}}{d t}=\gamma^{\prime} a \\
& \frac{d r_{2}}{d t}=(1-m) \gamma i \\
& \frac{d r_{3}}{d t}=\gamma q
\end{aligned}
$$

Although $m$ represents the isolation coefficient in the model, it is not an isolation ratio. In this study, we define $x$ as the isolation ratio calculation based on the final actual isolation cases $\left(r_{3}\right)$ and non-isolated cases $\left(r_{2}\right)$. Since isolation was only focused on cases who had symptoms (i) excluding asymptomatic, $r_{1}$ was excluded from the calculation of $x$. The calculation formula of $x$ was shown as follows:

$$
x=\frac{r_{3}}{r_{2}+r_{3}}
$$

We simulated 10 scenarios $(x=0.1,0.2, \ldots, 1.0)$ in which $x$ referred to the proportion of casa isolation.

\section{Indicator developed to assess the effectiveness of interventions}

We developed percentage of reduction (PR) under different intervention scenarios to assess the effectiveness of DIP and case isolation. The equation to calculate PR was shown as follows:

$$
P R_{i}=\frac{I_{0}-I_{i}}{I_{0}} \times 100 \%
$$

In the equation, $P R_{i}, I_{0}$, and $I_{i}$ refer to percentage of reduction under different intervention scenarios, incidence of shigellosis under the condition that no intervention was adopted, incidence of shigellosis under the condition that four intervention scenarios were simulated, respectively. 


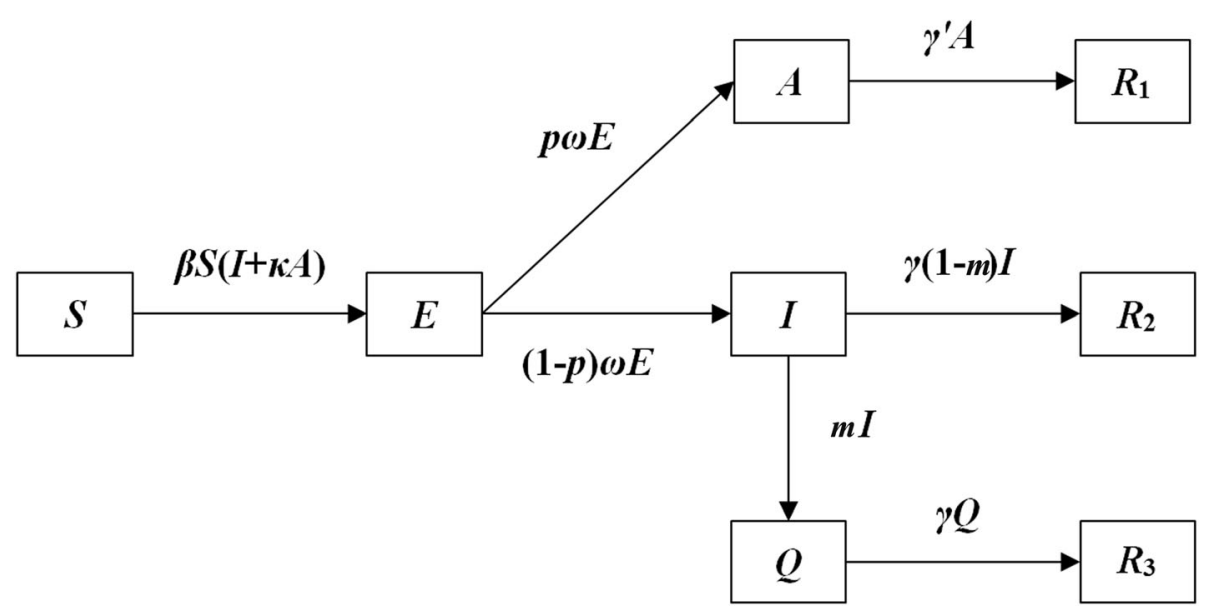

Fig. 1 The flowchart of SEIARQ model

Considering there is no standard threshold of PR to judge the satisfying of the intervention, we simulated PR at $50,60,70,80$, and $90 \%$ levels.

\section{Parameter estimation}

There are eight parameters $(b, k, \omega, p, \gamma, \gamma$ ' and $m)$ in the above models. According to our previous research [14], $k, \omega, p, \gamma$, and $\gamma^{\prime}$ are disease-specific parameters which could be estimated from literatures. The incubation period of Shigellosis is 1-4 days [2, 28], and commonly 1 days, therefore, $\omega=1.0$. The proportion of asymptomatic infection ranges from 0.0037 to 0.27 [29-31], and can be set $p=0.1$. The infectious period of symptomatic infection is 13.5 days [14], therefore, $\gamma=0.0741$. According to our previous research [14], the infectious period of asymptomatic infection could be simulated 5 weeks in our model, thus $\gamma^{\prime}=0.0286$. Due to reduction of shedding frequency, the relative transmissibility of asymptomatic individual $(k)$ was modeled to be a reduced quantity (0.3125) [14]. We set different values of $m$ until we got the ten target values of $x$. However, $b$ is scenarioor area-specific parameter which is various in different outbreaks even in different periods. Therefore, the parameter is confirmed by curve fitting by Model 1 to the collected data.

\section{Simulation method and statistical analysis}

In this study, we firstly analyzed the temporal distribution of the reported shigellosis cases, and divided the time series into several stages according to the homogeneity of reported incidence during the period. In each stage, an epidemic season was selected for the modelling and assessing the effectiveness of the interventions of DIP and case isolation.

Berkeley Madonna 8.3.18 (developed by Robert Macey and George Oster of the University of California at
Berkeley. Copyright $\odot 1993-2001$ Robert I. Macey \& George F. Oster) was employed for model simulation. Least root mean square (LRMS) and determination coefficient $\left(R^{2}\right)$ were adopted to judge the goodness of fit. The simulation methods were the same as the previously published researches [14, 17, 24, 32, 33]. The chi-square test was performed by SPSS 13.0 (IBM Corp., Armonk, NY, USA).

\section{Results}

\section{Basic characteristics of the reported cases}

During the study period, 130,770 shigellosis cases were reported in Hubei Province. According to the yearly incidence of the disease, the study period was divided into four stages: 1) stage 1 was from 2005 to 2008; 2) stage 2 was from 2009 to 2011; 3) stage 3 was from 2012 to 2014; and 4) stage 4 was from 2015 to 2017. The reported incidence decreased significantly (trend $X^{2}=8260.41, P<0.001$ ) among the four stages (Fig. 2).

\section{Model fitting}

One epidemic season, which is the time span between two lowest values of daily reported incidence during a year, was selected from each stage for the simulation (Table 1). By model fitting and the rule of LRMS, each selected epidemic season was divided into several subseasons (Fig. 3). The model fitted the data well except sub-season 2 in 2005-2006 season and sub-season 3 in 2013-2014 season (Table 1). The median of $R_{\text {eff }}$ was 1.13 (range: 0.86-1.21), 1.10 (range: 0.91-1.13), 1.09 (range: 0.92-1.92), and 1.03 (range: 0.94-1.22) in 20052006 season, 2010-2011 season, 2013-2014 season, and 2016-2017 season, respectively. 


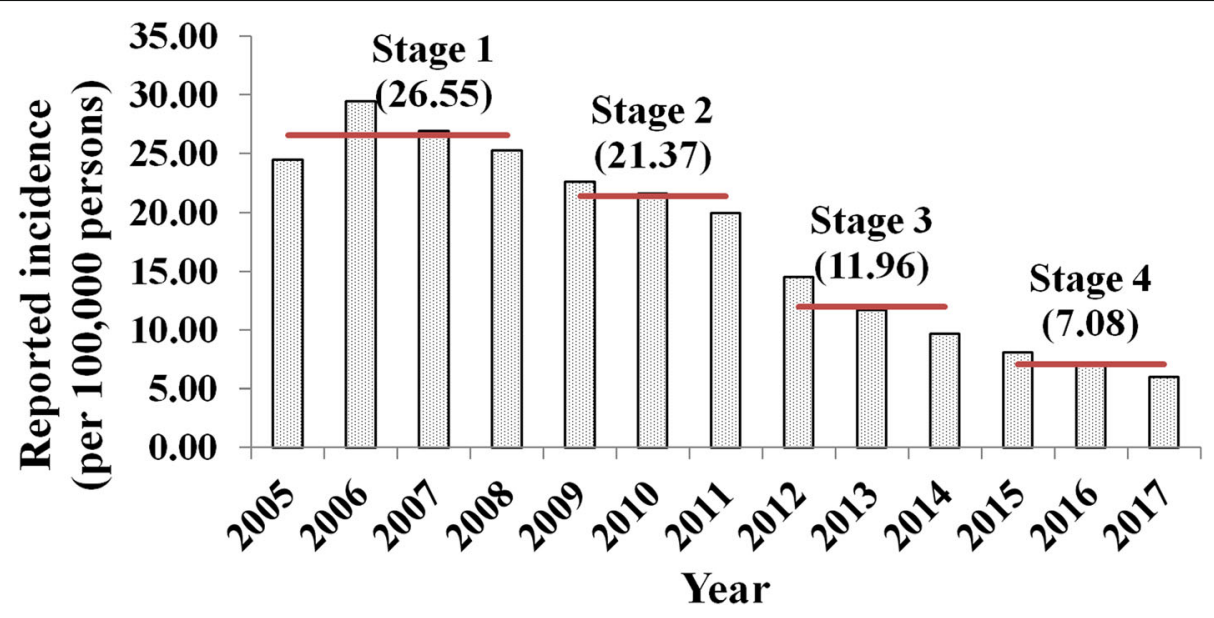

Fig. 2 Reported incidences and stages of shigellosis transmission from 2005 to 2017

\section{Effectiveness of DIP}

The incidence of shigellosis decreased sharply with the decrease of the infectious period through simulating the effectiveness of DIP in three scenarios $(\gamma=0.1,0.1429$, 0.3333) among 18 sub-seasons (Fig. 4).

\section{Effectiveness of case isolation}

By simulating 10 case isolation scenarios $(x=0.1,0.2, \ldots, 1.0)$ among 18 sub-seasons, the incidence of shigellosis decreased much sharply when $x$ increased (Fig. 5). Higher value of $x$ provided higher PR in each sub-season (Fig. 6). The value of $x$ was 0.25 (range: $0.1-0.4$ ), 0.3 (range: $0.2-0.5$ ), 0.4 (range: $0.2-0.6$ ), 0.55 (range: $0.3-0.8$ ), and 0.75 (range: 0.4-1.0), respectively to reach the PR levels of $50-90 \%$ (Table 2).

\section{Discussion}

In recent years, more and more prediction methods and models have been applied to the early warning analysis

Table 1 Basic features of the selected data for the simulation

\begin{tabular}{|c|c|c|c|c|c|c|c|c|c|}
\hline \multirow[t]{2}{*}{ Stages } & \multirow{2}{*}{$\begin{array}{l}\text { Epidemic seasons } \\
\text { selected }\end{array}$} & \multicolumn{3}{|c|}{ Sub-seasons included } & \multirow{2}{*}{$\begin{array}{l}\text { Number of } \\
\text { reported cases } \\
\text { included }\end{array}$} & \multirow[t]{2}{*}{$b$} & \multirow[t]{2}{*}{$R_{\text {eff }}$} & \multirow[t]{2}{*}{$R^{2}$} & \multirow[t]{2}{*}{$P$} \\
\hline & & $\overline{I D^{a}}$ & Start time & Stop time & & & & & \\
\hline \multirow[t]{4}{*}{ Stage 1} & $2005-2006$ & 1 & February 14, 2005 & July 26, 2005 & 6189 & 0.0900 & 1.19 & 0.94 & $<0.001$ \\
\hline & & 2 & July 27, 2005 & August 28, 2005 & 1917 & 0.0805 & 1.07 & 0.01 & 0.5570 \\
\hline & & 3 & August 29, 2005 & September 27, 2005 & 1917 & 0.0911 & 1.21 & 0.87 & $<0.001$ \\
\hline & & 4 & September 28, 2005 & February 2, 2006 & 3684 & 0.0649 & 0.86 & 0.98 & $<0.001$ \\
\hline \multirow[t]{3}{*}{ Stage 2} & 2010-2011 & 1 & January 31, 2010 & July 28, 2010 & 5896 & 0.0853 & 1.13 & 0.97 & $<0.001$ \\
\hline & & 2 & July 29, 2010 & September 9, 2010 & 2321 & 0.0833 & 1.10 & 0.73 & $<0.001$ \\
\hline & & 3 & September 10, 2010 & February 11, 2011 & 4305 & 0.0689 & 0.91 & 0.99 & $<0.001$ \\
\hline \multirow[t]{6}{*}{ Stage 3} & 2013-2014 & 1 & January 23, 2013 & May 16, 2013 & 1643 & 0.0818 & 1.08 & 0.78 & $<0.001$ \\
\hline & & 2 & May 17, 2013 & July 23, 2013 & 1558 & 0.0912 & 1.21 & 0.97 & $<0.001$ \\
\hline & & 3 & July 24, 2013 & September 2, 2013 & 1132 & 0.0826 & 1.09 & 0.07 & 0.0917 \\
\hline & & 4 & September 3, 2013 & October 3, 2013 & 675 & 0.0748 & 0.99 & 0.89 & $<0.001$ \\
\hline & & 5 & October 4, 2013 & October 9, 2013 & 164 & 0.1449 & 1.92 & 0.75 & 0.0266 \\
\hline & & 6 & October 10, 2013 & February 25, 2014 & 1826 & 0.0694 & 0.92 & 0.98 & $<0.001$ \\
\hline \multirow[t]{5}{*}{ Stage 4} & 2016-2017 & 1 & December 8, 2016 & March 17, 2017 & 694 & 0.0758 & 1.00 & 0.54 & $<0.001$ \\
\hline & & 2 & March 18, 2017 & June 12, 2017 & 953 & 0.0925 & 1.22 & 0.95 & $<0.001$ \\
\hline & & 3 & June 13, 2017 & July 11, 2017 & 381 & 0.0774 & 1.03 & 0.69 & $<0.001$ \\
\hline & & 4 & July 12, 2017 & August 9, 2017 & 412 & 0.0910 & 1.20 & 0.78 & $<0.001$ \\
\hline & & 5 & August 10, 2017 & December 31, 2017 & 1247 & 0.0712 & 0.94 & 0.94 & $<0.001$ \\
\hline
\end{tabular}



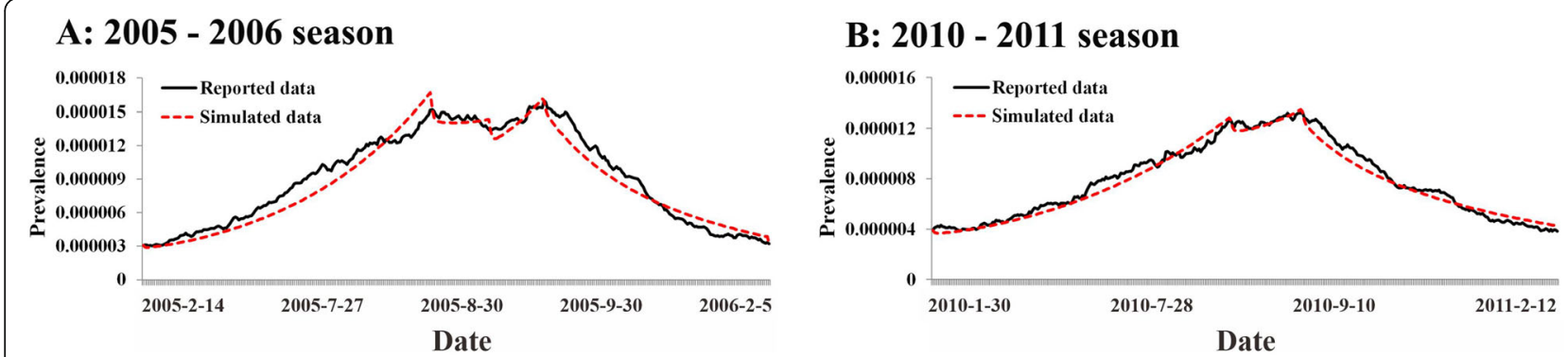

\section{C: 2013 - 2014 season}

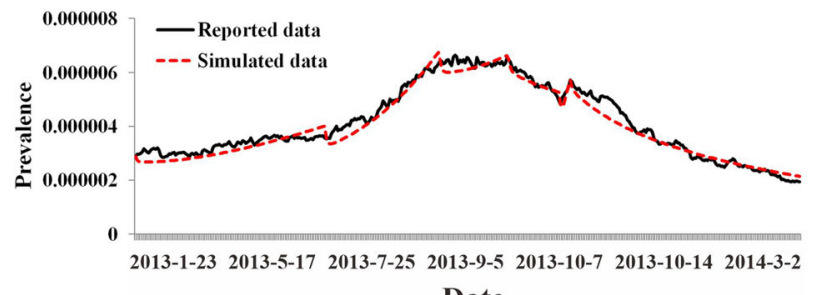

\section{D: 2016 - 2017 season}

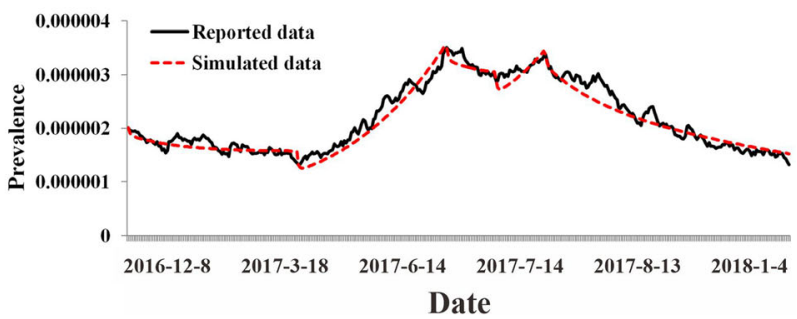

Fig. 3 The results of model fitting of SEIAR model to reported data in different stages. a, Curve fitting in 2005-2006 season; b, Curve fitting in 2010-2011 season; c, Curve fitting in 2013-2014 season; d, Curve fitting in 2016-2017 season

of infectious diseases [2, 3]. Therefore, the use of various methods to explore the occurrence and development of infectious diseases has been widely valued. This study, based on the incidence of shigellosis in Hubei Province from January 2005 to December 2017, we used the SEIAR model to simulate the effectiveness of reducing the infection period (DIP) of symptomatic individuals, and built the SEIARQ model to simulate the effectiveness of case isolation to find the best prevention and control measures. All of our models have been tested for goodness of fit, the results showed that more than $90 \%$ of $R^{2}$ are statistically significant, indicating the models have good applicability.

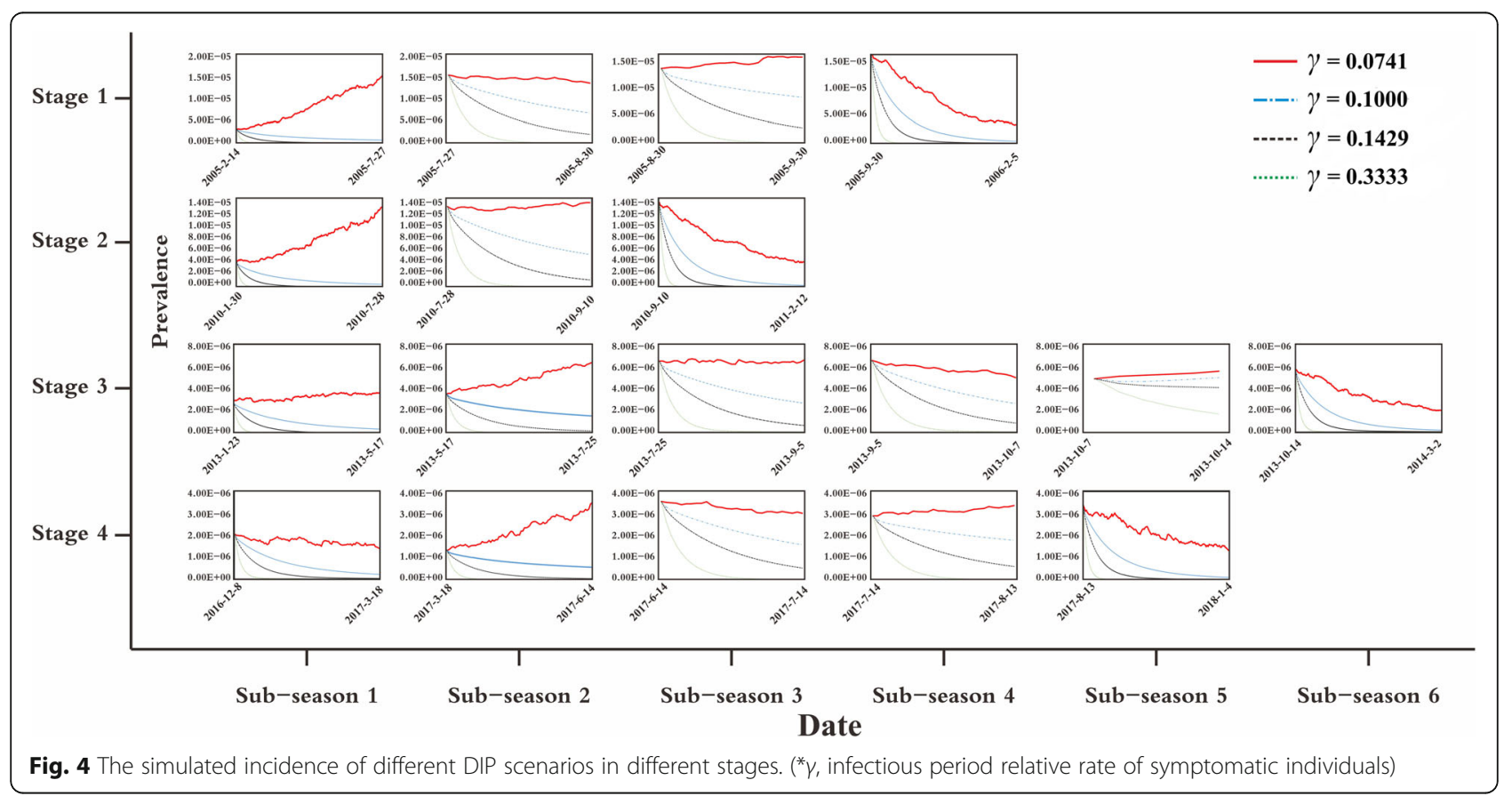



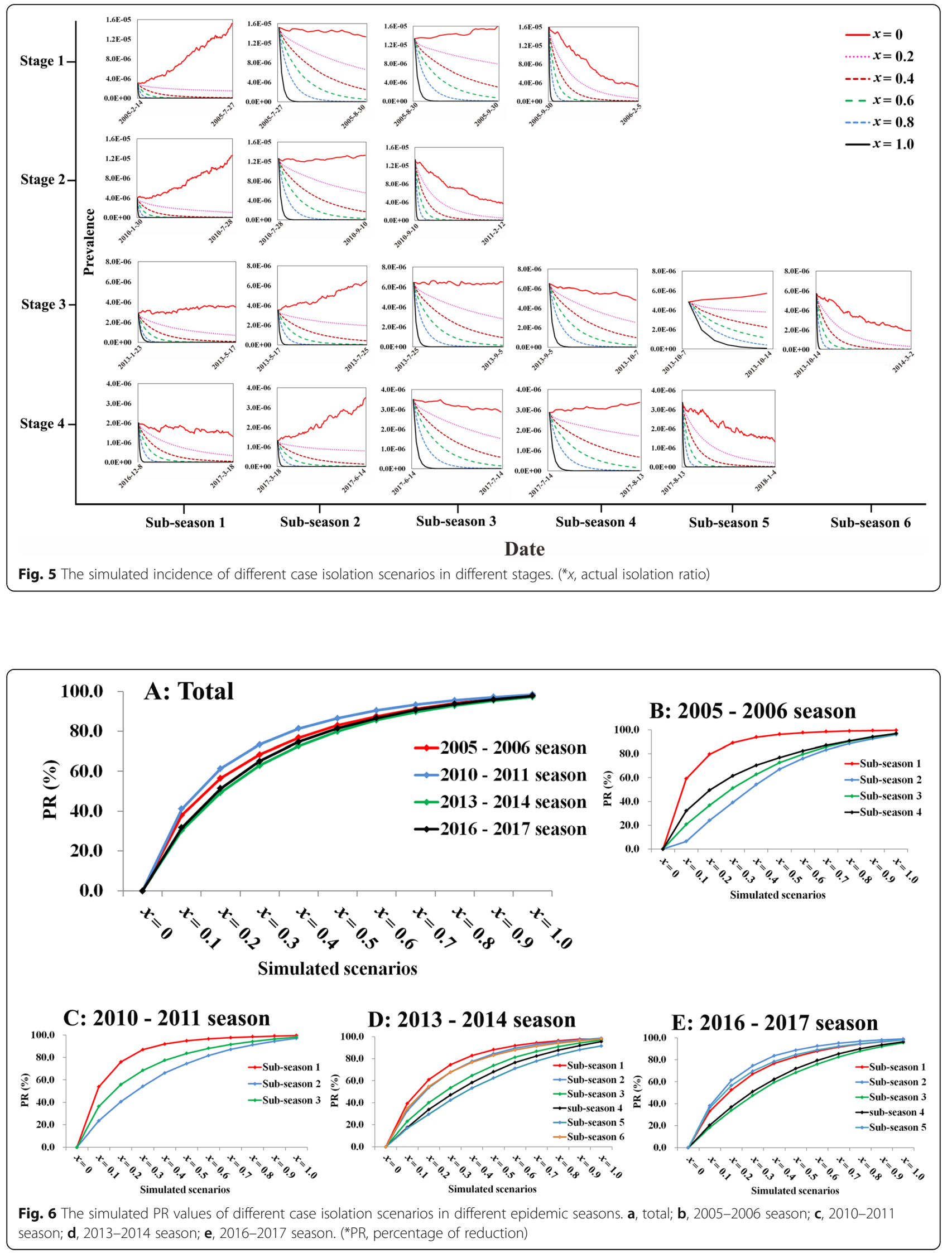
Table 2 The values of $x$ under different PR levels

\begin{tabular}{|c|c|c|c|c|c|c|c|c|c|c|c|c|c|c|c|c|c|c|c|}
\hline \multirow[t]{2}{*}{$\mathrm{PR}(\%)$} & \multicolumn{4}{|c|}{ Sub-seasons in 2005-2006 } & \multicolumn{3}{|c|}{ Sub-seasons in 2010-2011 } & \multicolumn{6}{|c|}{ Sub-seasons in 2013-2014 } & \multicolumn{5}{|c|}{ Sub-seasons in 2016-2017 } & \multirow[t]{2}{*}{ Median (range } \\
\hline & 1 & 2 & 3 & 4 & 1 & 2 & 3 & 1 & 2 & 3 & 4 & 5 & 6 & 1 & 2 & 3 & 4 & 5 & \\
\hline 50 & 0.1 & 0.4 & 0.3 & 0.3 & 0.1 & 0.3 & 0.2 & 0.2 & 0.2 & 0.3 & 0.4 & 0.4 & 0.2 & 0.2 & 0.2 & 0.4 & 0.3 & 0.2 & $0.25(0.1-0.4)$ \\
\hline 60 & 0.2 & 0.5 & 0.4 & 0.3 & 0.2 & 0.4 & 0.3 & 0.2 & 0.3 & 0.4 & 0.5 & 0.5 & 0.3 & 0.3 & 0.2 & 0.5 & 0.4 & 0.3 & $0.3(0.2-0.5)$ \\
\hline 70 & 0.2 & 0.6 & 0.5 & 0.4 & 0.2 & 0.5 & 0.4 & 0.3 & 0.4 & 0.5 & 0.6 & 0.6 & 0.4 & 0.4 & 0.3 & 0.6 & 0.5 & 0.4 & $0.4(0.2-0.6)$ \\
\hline 80 & 0.3 & 0.7 & 0.7 & 0.6 & 0.3 & 0.6 & 0.5 & 0.4 & 0.5 & 0.6 & 0.7 & 0.8 & 0.4 & 0.5 & 0.4 & 0.7 & 0.7 & 0.5 & $0.55(0.3-0.8)$ \\
\hline 90 & 0.4 & 0.9 & 0.8 & 0.8 & 0.4 & 0.8 & 0.7 & 0.6 & 0.7 & 0.8 & 0.9 & 1 & 0.7 & 0.7 & 0.6 & 0.9 & 0.8 & 0.7 & $0.75(0.4-1.0)$ \\
\hline
\end{tabular}

*PR Percentage of reduction

The results showed that the incidence of shigellosis decreased from 2005 to 2017, and could be divided into four stages. The decreased trend revealed that the incidence of the disease might decrease in the following years. Totally, 22 sub-seasons of four epidemic seasons (2005-2006 season, 2010-2011 season, 2013-2014 season, and 20162017 season) were selected for the simulating and assessing the effectiveness of DIP and case isolation. The results showed that the prevalence of the disease decreased sharply with DIP form 3 days $(\gamma=0.3333)$ to 13.5 days $(\gamma=0.0741)$ in the 22 sub-seasons. The results of the modelling also showed that the prevalence of the disease decreased sharply with the proportion of case isolation from $0 \%(x=0.1)$ to $100 \%(x=1)$ in the 22 sub-seasons. If we aimed to reach the PR levels of 50, 25\% (range: 10-40\%) of cases should be isolated. If we aimed to reach the PR levels of $90,75 \%$ (range: $40-100 \%$ ) of cases should be isolated. Therefore, case isolation and DIP interventions has high feasibility and effectiveness, and we strongly recommended to control the transmission of shigellosis.

The actual isolation ratio $x$ is affected by several aspects $[34,35]: 1)$ the sensitivity of the surveillance system which could monitor the cases in time when the symptoms onset; 2) After diagnosed, according to the severity of the disease, mild patients were generally recommended to be isolated at home, resulting in fewer patients undergoing effective isolation in the hospital.

In our previous research, an outbreak investigation was conducted in a school [14], but it was not investigated in the whole population, this study can provide relevant recommendations for the prevention and control of shigellosis in the whole population. Compared with some previous studies, although there are many epidemiological reports, but there are few reports on the ability to quantify the spread of shigellosis. Our research quantitatively evaluates the spread of shigellosis through mathematical modeling, and the effectiveness of interventions, thus providing a basis for relevant departments to make more appropriate prevention and control decisions.

\section{Limitations}

Our modeling on simulating countermeasures was based on the whole population. However, we did not consider the age-, sex- or area-specific situations. Another limitation is that we did not divide the interval between symptom onset and notification from IP.

\section{Conclusions}

Year heterogeneity of reported shigellosis incidence exists in Hubei Province, China. DIP and case isolation interventions have high effectiveness to control the transmission of shigellosis.

\section{Abbreviations \\ SEIAR: Susceptible - Exposed - Infectious / Asymptomatic - Recovered; DIP: Decreasing the infectious period; SIRW: Susceptible-Infectious- Recovered-Water; SEIARW: Susceptible-Exposed-Infectious/Asymptomatic- Recovered-Water; CISDCP: China Information System for Disease Control and Prevention; $R_{0}$ : Basic reproduction number; $R_{\text {eff. Effective reproduction }}$ number; IP: Infectious period; SEIARQ: Susceptible - Exposed - Infectious / Asymptomatic - Recovered - Quarantined; PR: Percentage of reduction; LRMS: Least root mean square; $R^{2}$ : Determination coefficient}

\section{Acknowledgments}

We thank the staff members at the hospitals, local health departments, and municipal- and county-level CDCs for their valuable assistance in coordinating data collection. We also thank the support from Undergraduate Innovation Practice Platform of School of Public Health, Xiamen University.

\section{Authors' contributions}

TC, QiC, BinZ, and YS designed the research; QiC collected the data; TC, JR, $\mathrm{QiC}, \mathrm{QC}, \mathrm{QH}$, and ZL conceived the experiments, TC, JR, MNH, ZZ, YW, XL, SY and $\mathrm{YC}$ conducted the experiments and analyzed the results; TC, JR and BZ wrote the manuscript. All authors read and approved the final manuscript.

\section{Funding}

This study was partly supported by the Open Research Fund of State Key Laboratory of Molecular Vaccinology and Molecular Diagnostics (SKLV D2019KF005), the Science and Technology Program of Fujian Province (No: 2020Y0002), the Xiamen New Coronavirus Prevention and Control Emergency Tackling Special Topic Program (No: 3502Z2020YJ03), and the XMU Training Program of Innovation and Enterpreneurship for Undergraduates. (No: 2019Y0805).

\section{Availability of data and materials}

The datasets used and analyzed during the current study are available from Dr. Qi Chen (chenqi8700@qq.com) on reasonable request.

\section{Ethics approval and consent to participate}

This effort of outbreak control and investigation was part of CDC's routine responsibility in Hubei Province; therefore, institutional review and informed consent were waived by Medical Ethics Committee of Hubei Center for Disease Control and Prevention on the following grounds: (1) all data analyzed were anonymized; (2) neither medical intervention nor biological samples were involved; (3) study procedures and results would not affect clinical management of patients in any form. 


\section{Consent for publication}

Not applicable.

\section{Competing interests}

The authors declare that they have no competing interests.

\section{Author details}

'State Key Laboratory of Molecular Vaccinology and Molecular Diagnostics, School of Public Health, Xiamen University, 4221-117 South Xiang'an Road, Xiang'an District, Xiamen City, Fujian Province, People's Republic of China. ${ }^{2}$ Hubei Provincial Center for Disease Control and Prevention, Wuhan City, Hubei Province, People's Republic of China. ${ }^{3}$ Medical Insurance Office, Xiang'an Hospital of Xiamen University, Xiamen City, Fujian Province, People's Republic of China. ${ }^{4}$ Division of Public Health, School of Medicine, University of Utah, 201 Presidents Circle, Salt Lake City, UT 84112, USA. ${ }^{5}$ Medical College, Xiamen University, Xiamen City, Fujian Province, People's Republic of China. 'Laboratory Department, Xiang'an Hospital of Xiamen University, State Key Laboratory of Molecular Vaccinology and Molecular Diagnosis, Xiamen City, Fujian Province, People's Republic of China.

\section{Received: 25 November 2019 Accepted: 17 August 2020} Published online: 01 September 2020

\section{References}

1. Khalil IA, Troeger C, Blacker BF, Rao PC, Brown A, Atherly DE, et al. Morbidity and mortality due to shigella and enterotoxigenic Escherichia coli diarrhoea: the Global Burden of Disease Study 1990-2016. Lancet Infect Dis. 2018; 18(11):1229-40. https://doi.org/10.1016/S1473-3099(18)30475-4. PubMed PMID: WOS:000448325300032.

2. Kotloff KL, Riddle MS, Platts-Mills JA, Pavlinac P, Zaidi AKM. Shigellosis Lancet. 2018;391(10122):801-12. https://doi.org/10.1016/S01406736(17)33296-8 Epub 2017/12/20. PubMed PMID: 29254859.

3. Tickell KD, Brander RL, Atlas HE, Pernica JM, Walson JL, Pavlinac PB. Identification and management of Shigella infection in children with diarrhoea: a systematic review and meta-analysis. Lancet Glob Health. 2017; 5(12):e1235-e48. https://doi.org/10.1016/S2214-109X(17)30392-3 Epub 2017/ 11/15. PubMed PMID: 29132613; PubMed Central PMCID: PMCPMC5695759.

4. Wu HH, Shen YT, Chiou CS, Fang CT, Lo YC. Shigellosis outbreak among MSM living with HIV: a case-control study in Taiwan, 2015-2016. Sex Transm Infect. 2019;95(1):67-70. https://doi.org/10.1136/sextrans-2017-053410 Epub 2018/03/15. PubMed PMID: 29535222.

5. George CM, Ahmed S, Talukder KA, Azmi IJ, Perin J, Sack RB, et al. Shigella Infections in Household Contacts of Pediatric Shigellosis Patients in Rural Bangladesh. j. 2015;21(11):2006-13. https://doi.org/10.3201/eid2111.150333 Epub 2015/10/21. PubMed PMID: 26484778; PubMed Central PMCID: PMCP MC4622242.

6. Toro C, Arroyo A, Sarria A, Iglesias N, Enriquez A, Baquero M, et al. Shigellosis in subjects with Traveler's diarrhea versus domestically acquired diarrhea: implications for antimicrobial therapy and human immunodeficiency virus surveillance. Am J Trop Med Hyg. 2015;93(3):491-6. https://doi.org/10.4269/ajtmh.14-0804 Epub 2015/07/22. PubMed PMID: 26195465; PubMed Central PMCID: PMCPMC4559685.

7. Choe YJ, Choe SA, Cho SI. Importation of travel-related infectious diseases is increasing in South Korea: an analysis of salmonellosis, shigellosis, malaria, and dengue surveillance data. Travel Med Infect Dis. 2017;19:22-7. https://doi.org/10.1016/j.tmaid.2017.09.003 Epub 2017/09/19. PubMed PMID: 28919170.

8. Mani S, Wierzba T, Walker RI. Status of vaccine research and development for Shigella. Vaccine. 2016;34(26):2887-94. https://doi.org/10.1016/j.vaccine. 2016.02.075 PubMed PMID: 26979135.

9. Farag TH, Faruque AS, Wu Y, Das SK, Hossain A, Ahmed S, et al. Housefly population density correlates with shigellosis among children in Mirzapur, Bangladesh: a time series analysis. PLoS Negl Trop Dis. 2013;7(6):e2280. https://doi.org/10.1371/journal.pntd.0002280 Epub 2013/07/03. PubMed PMID: 23818998; PubMed Central PMCID: PMCPMC3688559.

10. Gonzalez-Torralba A, Alos Jl. Shigellosis, the importance of hygiene in prevention. Enferm Infecc Microbiol Clin. 2015;33(3):143-4. https://doi.org/ 10.1016/.jeimc.2014.11.001 Epub 2014/12/30. PubMed PMID: 25541007.

11. Bhattacharya SK, Sur D, Mahalanabis D. Public health significance of shigellosis. Indian Pediatr. 2012:49(4):269-70 Epub 2012/05/09. PubMed PMID: 22565071
12. World Health Organization. Shigellosis: disease burden, epidemiology and case management. Wkly Epidemiol Rec. 2005;80(11):94-9.

13. Schulte JM, Williams L, Asghar J, Dang T, Bedwell S, Guerrero K, et al. How we didn't clean up until we washed our hands: shigellosis in an elementary and middle school in North Texas. South Med J. 2012;105(1):1-4. https://doi. org/10.1097/SMJ.0b013e31823c411e Epub 2011/12/23. PubMed PMID: 22189658.

14. Chen T, Leung RK, Zhou Z, Liu R, Zhang X, Zhang L. Investigation of key interventions for shigellosis outbreak control in China. PLoS One. 2014;9(4): e95006. https://doi.org/10.1371/journal.pone.0095006 Epub 2014/04/17. PubMed PMID: 24736407; PubMed Central PMCID: PMCPMC3988114.

15. Wang K, Song W, Li J, Lu W, Yu J, Han X. The use of an autoregressive integrated moving average model for prediction of the incidence of dysentery in Jiangsu, China. Asia Pac J Public Health. 2016;28(4):336-46. https://doi.org/10.1177/1010539516645153 Epub 2016/04/24. PubMed PMID: 27106828

16. Jones RC, Liberatore M, Fernandez JR, Gerber SI. Use of a prospective spacetime scan statistic to prioritize shigellosis case investigations in an urban jurisdiction. Public Health Rep. 2006:121(2):133-9. https://doi.org/10.1177/ 003335490612100206 Epub 2006/03/15. PubMed PMID: 16528945; PubMed Central PMCID: PMCPMC1525257.

17. Chen T, Gu H, Leung RK, Liu R, Chen Q, Wu Y, et al. Evidence-based interventions of Norovirus outbreaks in China. BMC Public Health. 2016;16(1): 1072. https:/doi.org/10.1186/s12889-016-3716-3 PubMed PMID: 27729034.

18. Wang T, Liu S, Qian X, Shimizu T, Dente SMR, Hashimoto S, et al. Assessment of the municipal water cycle in China. Sci Total Environ. 2017; 607-608:761-70. https://doi.org/10.1016/.jscitotenv.2017.07.072 PubMed PMID: 28711006

19. He F, Han K, Liu L, Sun W, Zhang L, Zhu B, et al. Shigellosis outbreak associated with contaminated well water in a rural elementary school: Sichuan Province, China, June 7-16, 2009. PloS one. 2012;7(10):e47239. https://doi.org/10.1371/journal.pone.0047239 Epub 2012/10/17. PubMed PMID: 23071767; PubMed Central PMCID: PMCPmc3468462.

20. Chen $T$, Chen $T$, Liu R, Xu C, Wang D, Chen F, et al. Transmissibility of the influenza virus during influenza outbreaks and related asymptomatic infection in mainland China, 2005-2013. PLoS One. 2016;11(11):e0166180. https://doi.org/10.1371/journal.pone.0166180 PubMed PMID: 27880774.

21. Chen T, Huang Y, Liu R, Xie Z, Chen S, Hu G. Evaluating the effects of common control measures for influenza a ( $\mathrm{H} 1 \mathrm{~N} 1)$ outbreak at school in China: a modeling study. PLoS One. 2017;12(5):e0177672. https://doi.org/10. 1371/journal.pone.0177672 PubMed PMID: 28542360

22. Xu W, Chen T, Dong X, Kong M, Lv X, Li L. Outbreak detection and evaluation of a school-based influenza-like-illness syndromic surveillance in Tianjin. China PloS one. 2017;12(9):e0184527. https://doi.org/10.1371/journal. pone.0184527 PubMed PMID: 28886143.

23. Chen $Q$, Rui J, Hu Q, Peng Y, Zhang H, Zhao Z, et al. Epidemiological characteristics and transmissibility of shigellosis in Hubei Province, China, 2005-2017. BMC Infect Dis. 2020;20(1):272. https://doi.org/10.1186/s12879020-04976-x Epub 2020/04/09. PubMed PMID: 32264846; PubMed Central PMCID: PMCPMC7136996.

24. Chen T, Ka-Kit Leung R, Liu R, Chen F, Zhang X, Zhao J, et al. Risk of imported Ebola virus disease in China. Travel Med Infect Dis. 2014;12(6 Pt A): 650-8. https://doi.org/10.1016/j.tmaid.2014.10.015 PubMed PMID: 25467086.

25. Heffernan JM, Smith RJ, Wahl LM. Perspectives on the basic reproductive ratio. J Royal Society, Interface / the Royal Society. 2005;2(4):281-93. https:// doi.org/10.1098/rsif.2005.0042 Epub 2006/07/20. PubMed PMID: 16849186; PubMed Central PMCID: PMCPmc1578275.

26. Chen TM, Chen QP, Liu RC, Szot A, Chen SL, Zhao J, et al. The transmissibility estimation of influenza with early stage data of small-scale outbreaks in Changsha, China, 2005-2013. Epidemiol Infect. 2017;145(3):42433. https://doi.org/10.1017/S0950268816002508 PubMed PMID: 27834157; PubMed Central PMCID: PMC5244440

27. Wang $Y$, Feng Z, Yang Y, Self S, Gao Y, Longini IM, et al. Hand, foot, and mouth disease in China: patterns of spread and transmissibility. Epidemiology. 2011;22(6):781-92. https://doi.org/10.1097/EDE. Ob013e318231d67a PubMed PMID: 21968769; PubMed Central PMCID: PMC3246273.

28. Xiao GG, Fan J, Deng JJ, Chen CH, Zhou W, Li XH, et al. A school outbreak of Shigella sonnei infection in China: clinical features, antibiotic susceptibility and molecular epidemiology. Indian Pediatr. 2012;49(4):287-90 Epub 2011/10/14. PubMed PMID: 21992857. 
29. Bovee L, Whelan J, Sonder GJ, van Dam AP, van den Hoek A. Risk factors for secondary transmission of Shigella infection within households: implications for current prevention policy. BMC Infect Dis. 2012;12:347. https://doi.org/10. 1186/1471-2334-12-347 Epub 2012/12/14. PubMed PMID: 23234356; PubMed Central PMCID: PMCPmc3561077.

30. Qadri MH, Ai-Gamdi MA, Al-Harfi RA. Asymptomatic salmonella, Shigella and intestinal parasites among primary school children in the eastern province. $J$ Family Community Med. 1995;2(2):36-40 Epub 1995/07/01. PubMed PMID: 23012224; PubMed Central PMCID: PMCPmc3437126.

31. Khan Al, Talukder KA, Huq S, Mondal D, Malek MA, Dutta DK, et al. Detection of intra-familial transmission of shigella infection using conventional serotyping and pulsed-field gel electrophoresis. Epidemiol Infect. 2006;134(3):605-11. https://doi.org/10.1017/s0950268805005534 Epub 2005/11/18. PubMed PMID: 16288683; PubMed Central PMCID: PMCPmc2870428.

32. Chen T, Zhao B, Liu R, Zhang X, Xie Z, Chen S. Simulation of key interventions for seasonal influenza outbreak control at school in Changsha, China. J Int Med Res. 2018;300060518764268. https://doi.org/10.1177/ 0300060518764268 PubMed PMID: 29569977.

33. Liu R, Leung RK, Chen T, Zhang X, Chen F, Chen S, et al. The effectiveness of age-specific isolation policies on epidemics of influenza a (H1N1) in a large City in central South China. PLoS One. 2015;10(7):e0132588. https:// doi.org/10.1371/journal.pone.0132588 PubMed PMID: 26161740; PubMed Central PMCID: PMC4498797.

34. Jesudason MV. Shigella isolation in Vellore, South India (1997-2001). Indian J Med Res. 2002;115:11-3 Epub 2002/11/12. PubMed PMID: 12424931

35. Sur D, Ramamurthy T, Deen J, Bhattacharya SK. Shigellosis : challenges \& management issues. Indian J Med Res. 2004;120(5):454-62 Epub 2004/12/14. PubMed PMID: 15591629.

\section{Publisher's Note}

Springer Nature remains neutral with regard to jurisdictional claims in published maps and institutional affiliations.

Ready to submit your research? Choose BMC and benefit from:

- fast, convenient online submission

- thorough peer review by experienced researchers in your field

- rapid publication on acceptance

- support for research data, including large and complex data types

- gold Open Access which fosters wider collaboration and increased citations

- maximum visibility for your research: over $100 \mathrm{M}$ website views per year

At $\mathrm{BMC}$, research is always in progress.

Learn more biomedcentral.com/submissions 